\title{
Correction to: Ten weeks of branched-chain amino acid supplementation improves select performance and immunological variables in trained cyclists
}

\author{
Wesley C. Kephart ${ }^{1} \cdot$ Taylor D. Wachs ${ }^{1} \cdot$ R. Mac Thompson ${ }^{1}$. C. Brooks Mobley ${ }^{1} \cdot$ Carlton D. Fox $^{1}$. \\ James R. McDonald ${ }^{1}$ • Brian S. Ferguson ${ }^{1} \cdot$ Kaelin C. Young $^{2} \cdot$ Ben Nie $^{3}$ • Jeffrey S. Martin ${ }^{1,4} \cdot$ Joseph M. Company $^{5}$. \\ David D. Pascoe ${ }^{1,4} \cdot$ Robert D. Arnold ${ }^{3} \cdot$ Jordan R. Moon ${ }^{6} \cdot$ Michael D. Roberts $^{1,4}$
}

Published online: 11 August 2018

(c) Springer-Verlag GmbH Austria, part of Springer Nature 2018

\section{Correction to: Amino Acids (2016) 48:779-789 https://doi.org/10.1007/s00726-015-2125-8}

The authors claim that their names were incorrectly listed on PubMed.

For the author R. Mac Thompson, the first name should be R. Mac and the last name should be Thompson. On SpringerLink the name is listed correctly, but on PubMed he is listed as Mac Thompson R.

The original article can be found online at https://doi.org/10.1007/ s00726-015-2125-8.

Michael D. Roberts

mdr0024@auburn.edu

Wesley C. Kephart

wck0007@auburn.edu

Taylor D. Wachs

tdw0013@auburn.edu

R. Mac Thompson

rmt0010@auburn.edu

C. Brooks Mobley

moblecb@auburn.edu

Carlton D. Fox

cdf0007@auburn.edu

James R. McDonald

jrm0013@auburn.edu

Brian S. Ferguson

bsf0003@auburn.edu

Kaelin C. Young

kaelin.young@wichita.edu

Ben Nie

bzn0004@auburn.edu

Jeffrey S. Martin

jmartin@auburn.vcom.edu
For another author C. Brooks Mobley, the first name should be C. Brooks and the last name should be Mobley. On SpringerLink the name is listed correctly, but on PubMed he is listed as Brooks Mobley C.

Joseph M. Company

joe@endurancecompany.com

David D. Pascoe

pascodd@auburn.edu

Robert D. Arnold

rda0007@auburn.edu

Jordan R. Moon

jordan@musclepharm.com

1 School of Kinesiology, Molecular and Applied Sciences Laboratory, Auburn University, 301 Wire Road, Office 286, Auburn, AL 36849, USA

2 Wichita State University, Wichita, KS, USA

3 Harrison School of Pharmacy, Auburn University, Auburn, AL, USA

4 Edward Via College of Osteopathic Medicine, Auburn Campus, Auburn, AL, USA

5 Endurance Company, LLC, Bloomington, IL, USA

6 MusclePharm Sports Science Institute, Denver, CO, USA 